\title{
MJN \\ RELATIONSHIP BETWEEN THE KNOWLEDGE ON SELF-EFFICACY \\ ABOUT COUNSELING AND STOMA SITE MARKING FOR PATIENTS UNDERGOING STOMA SURGERY IN ETNS
}

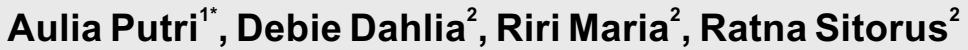 \\ ${ }^{I}$ Faculty of Nursing, Indonesia University, Indonesia \\ ${ }^{2}$ Medical Surgical Nursing Departement, Indonesia University, Indonesia \\ *Corresponding Author's Email: aulia_2803@yahoo.com
}

\begin{abstract}
Stoma complications may affect physical and psychological aspects in patients' life. The implementation of counseling and stoma site marking prior to surgery can reduce the risk of complications and improve the quality the life of the patients. Enterostomal Therapy Nurse (ETN) is a nurse graduated of an educational program called ETNEP (Enterostomal Therapy Nurse Education Program). Self-efficacy of ETNs plays vital role in application of counselling and stoma site marking. This study aimed to evaluate knowledge and self-efficacy of ETNs and to investigate the relationship between the knowledge and self-efficacy about counseling and stoma site marking in ETNs.

A cross sectional design was used which involved 81 ETNs in Indonesia. The study was conducted in 2017. The data were collected by using online questionnaire in a 3-part on ETNs's demographic characteristics, knowledge of counseling and stoma site marking (27 questions) and self-efficacy (33 questions). The data collecting process designed by google form then analyzed by using Chi Square test.

Findings showed that there was a statistically significant correlation between the knowledge and selfefficacy $(p=0,008, \mathrm{OR}=3,808)$. An increase in knowledge corresponded with an improvement in the selfefficacy about counseling and stoma site marking in ETNs. This recommended every hospitals with stoma care may improve ETNs knowledge about counseling and stoma site marking periodically.
\end{abstract}

Keywords: Counseling, ETN, Stoma site marking

\section{INTRODUCTION}

Basically, stoma surgery is indicated by many conditions such as colorectal cancer, bladder cancer, ulcerative colitis, Crohn's disease, diverticulitis, obstruction, urinary and fecal incontinence, and trauma (Swan, 2011). The number of patients those who have performed stoma surgery in the United States is estimated 650,000 to 730,000 people (Cross, Roe \& Wang, 2014). Then, approximately 1 million people living in North America had stomas, and more than 120,000 new stomas were created each year (Pittman, 2014). However, the most common cause of stoma is colorectal cancer. Increasing incidence of colorectal cancer is an indicator for number of patients with stomas
(Indonesian Ostomy Association, 2010). The American Cancer Society estimated that 27.150 men and 23.110 women in the US will die of colorectal cancer in 2017. This refer to the actual numbers of colorectal cancer deaths from 2000 through 2014 that colorectal cancer is the third largest cancer and will become the second main cause of death in the United States (The American Cancer Society, 2017). In Indonesia, the incidence of colorectal cancer is 12.8 per 100,000 population and the mortality is $9.5 \%$ of all cases in cancer (Ministry of Health Indonesia, 2012).

Nevertheless, the patients with stoma reported that stoma affected their lives both physically and psychologically. Physically, patients have a risk for stomal 
and peristomal complications while psychologically the difficulties are in adaptation with stoma. Consequently, the experiences of anxiety, fear, depression, body image disturbance, anger, and rejection may occur (Pittman, 2014). The World Council of Enterostomal Therapists Internasional Ostomy (2014) (Zulkowski, Ayello \& Stelton, 2014) recommended the counseling and stoma site marking to prevent complication risk of stoma. Counseling is a process of transfering the informations regarding stoma in order to minimize the patient's anxiety and to distruct any incorrect informations about stoma (Cronin, 2012). The informations provided lifestyle changes with stoma, equipments needed for stoma, the stoma appearance and the importance of family supports. It may an effective way to prepare the patients' prior to stoma surgery (Bobbit, 2003). Subsequently, stoma site marking is an assessment of abdomen in various positions to obtain the appropriate position for stoma. This assesment purposed to decrease post-operative complications risks such as leakage, ischemic, obstruction, parastomal herniation, prolapse, stoma retraction, mucocutaneous separation, stenosis and bleeding (Person et al., 2012). In addition, in the Charter of Ostomate Rights stated that two important rights of patients with stoma surgery are counseling and stoma site marking (International Ostomy Association, 2004). Furthermore, the goal in caring patients of colorectal cancer with stoma may associated with the effective counseling and stoma site marking and supported by a standardized operation procedure (Maryunani \& Haryanto, 2016).

Absolutely, counseling and stoma site marking are highly recommended, but in many healthcare service stoma care did not apply to this program. In Indonesia, counseling and stoma site marking before surgery were not implemented appropriately even though in many hospitals have Enterostomal Therapy Nurse (ETN). Baich, Wilson \& Cumming, (2010) described ETN as a nurse graduated from school or accredited educational program called ETNEP (Enterostomal Therapy Nurse Education Program). Moreover, World Council of Enterostomal Therapists (Stelton, Zulkowski \& Ayello, 2014) mentioned the ETN is a nurse who can provide enterostomal therapy, performing care stoma, wound and continental care. Therefore, ETNs are expected to play an important role in preparing patients before stoma surgery that including counselling and stoma site marking.

A previous study by Nakhaei \& Mofrad (2015) found that knowledge and self-efficacy of teams are the most important point in implementing the evidence based on clinical practice. Knowledge is often defined as a belief that is something true and justified (Hunt, 2003). While self-efficacy, according to the theory of self-efficacy by Bandura (1997) stated that selfefficacy is the belief and confidence within a person in performing a behavior. Self-efficacy determines how much effort will be done and how long the individual will survive to face unpleasant obstacles. Finally, this study aimed to evaluate knowledge and self-efficacy of ETNs in Indonesia and to investigate the relationship between the knowledge and self-efficacy about counseling and stoma site marking in ETNs.

\section{RESEARCH METHODOLOGY}

In this cross sectional study, 81 ETNs who registered as a member of Indonesia Wound Ostomy and Continen (InWOCNA) were involved. The ETNs was determined by the following inclusion criteria: (1) ETNs working in hospital/healthcare with patients prior to stoma surgery

(2) ETNs in clinical experience more than 3 years for undergraduate, (3) ETNs in clinical experience more than 2 years for postgraduate.

The study obtained approval from the research and ethical committee of Indonesia University. The collecting data was conducted in the year 2017. The data collection tool is a questionnaire that contained three sections: (a) characteristics of ETNs (age, gender, working experience as ETN) (b) knowledge about counseling and stoma site marking (c) self-efficacy about counseling and stoma site marking. The content and construct validity of the questionnaire was revised by two experts, one of whom is the President of InWOCNA period 2015-2020. Reliability analysis was conducted for testing the reliability of knowledge and self-efficacy construct. Internal consistency of these sections of the questionnaire was calculated using Cronbach's alpha technique $(0,869$ for knowlegde and 0,97 for self-efficacy). To investigate the knowledge of ETNs there were 27 multiple choice questions developed by combining several references and 
guidelines related to the implementation of counseling and stoma site marking. The guidelines obtained from several world stoma associations, such as The Canadian Association for Enterostomal Therapy (CAET) 2016, Clinical guideline for Stomal Therapy Nursing Practice 2013, WOCN Society and ASCRS Position Satatement on preoperative stoma site marking 2014 and journals about stoma. In addition, the questionnaire also refers to the guideline of ETNEP content by 'World Council of Enterostomal Theapists (WCET)'. Whereas, to assess ETN's self-efficacy there were 33 questions used a Scale 1-9 (1=Uncertain, 9=Certain). ETN is required to answer each questions based on their confidence about counseling and stoma site marking. The questionnaires created by modifying The Nursing Self-Efficacy Scale (NCSES) which consists of 66 statements about the beliefs of nurses in implementing nursing competences. Furthermore, all questionnaires were converted into a survey sheet created by google form Google Drive. The process of data collection was done by utilizing the internet services. The questionnaire can be accessed by computer or gadget during availability of internet access. Data analysis used Chi Square Test at the significance level of $\alpha=0.05$ to investigate the relationship between knowledge and self-efficacy about counseling and stoma site marking in ETNs.

\section{RESULTS AND DISCUSSION}

Findings showed that most of the participants $(60.5 \%)$ were female, $74.1 \%$ were in $30-50$ years old and $64.2 \%$ had experienced as ETN 5-10 years.

\section{Table 1: Demographic Characteristics of the ETNs Participating in this Study}

\begin{tabular}{|c|l|l|}
\hline Characteristic & Frequency & Persentage \\
\hline Age : & & \\
\hline$<30$ years old & 10 & 12.3 \\
\hline $30-50$ years old & 60 & 74.1 \\
\hline$>50$ yeras old & 11 & 13.6 \\
\hline Gender: & & \\
\hline Male & 32 & 39.5 \\
\hline Female & 49 & 60.5 \\
\hline Working experience as ETN: & & \\
\hline$<5$ years & 19 & 23.5 \\
\hline $5-10$ years & 52 & 64.2 \\
\hline$>10$ years & 10 & 12.3 \\
\hline
\end{tabular}

The table explained that majority of ETNs were female at the middle age of their working carrier and they were working for more than five years in ETN. Basiclly, based on "From Novice to Expert Theory " by Patricia Banner ETNs were not in the level of novice anymore but higher. It may be advance beginner, competent, proficient or expert. The research also showed that 58\% ETNs in a good knowledge about councelling and stoma site marking.

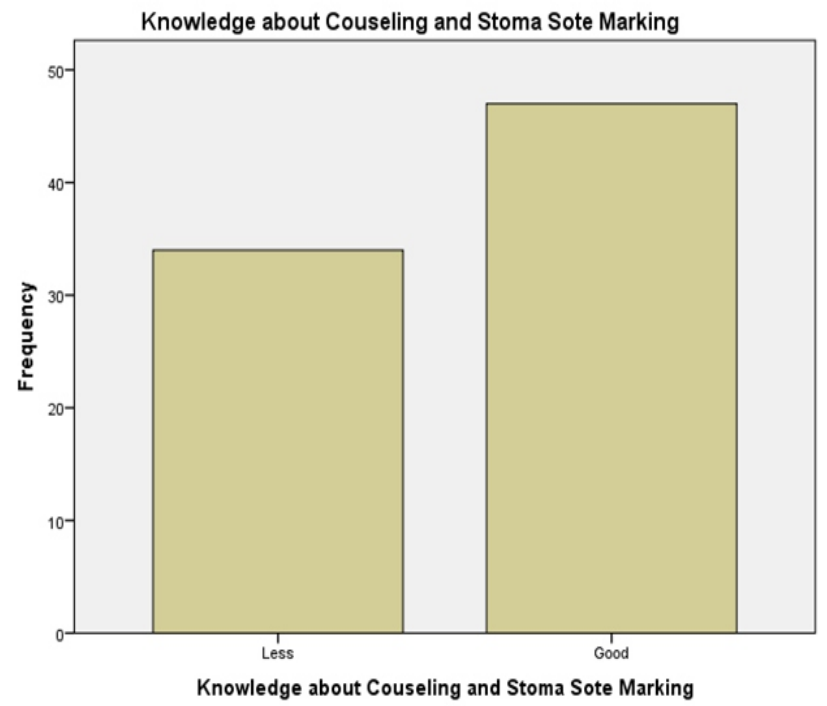

Figure 1: Knowledge About Counseling and Stoma Site Marking in ETNs in Indonesia

It was shown that basically the nurses followed the ETNEP were a competent and experienced nurses, so the theories and practices about stoma can be understood easily. Eventually, the percentage of ETNs in good knowledge is higher than ETNS in less of knowledge. ETNs (42\%) in less of knowledge may due to the absence of evaluation about theories and practices obtained before in ETNEP. Consequently, ETNs got any doubt and uncertainty about the correct answer of the questions. This assumption is reinforced by Hunt (2003) who said that knowledge is not only the process to obtain the information but also how it can be survived and stored in memory for a long time. This reveals the importance for a teacher or instructor to consider the reexamined, reinterpreted, and reevaluated process in order to make it can be useful in the future (Hunt, 2003 ). Findings also defined that $56.8 \%$ had a high selfefficacy about counceling and stoma site marking. 


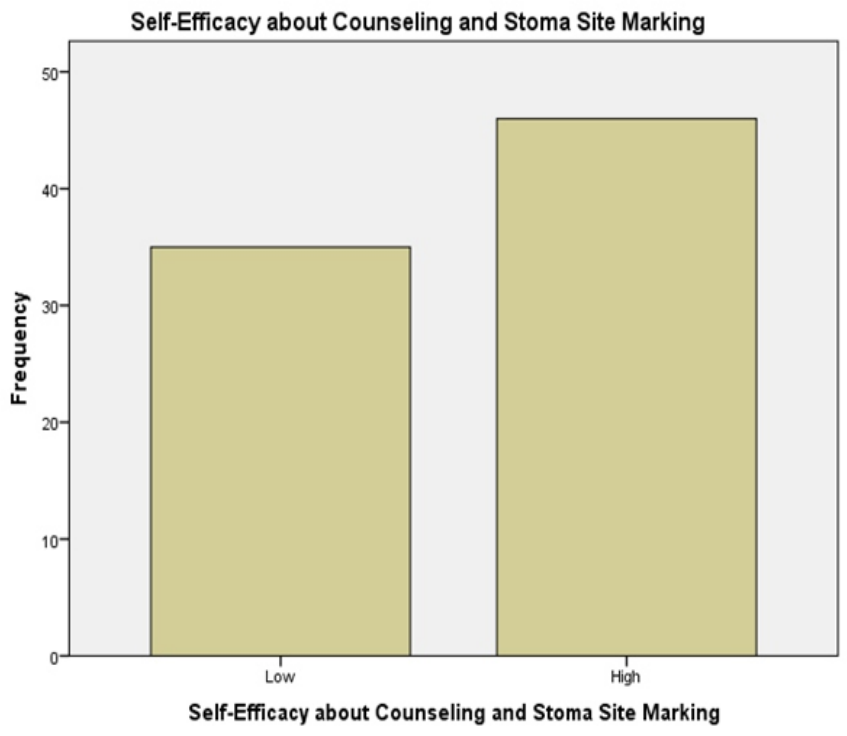

Figure 2: Self-efficacy About Counseling and Stoma Site Marking in ETNs in Indonesia

The figure shown that the precentage of ETNs in high self-efficacy are higher than ETNs in low selfefficacy. The uncertainty statements of ETN's in some questions about counseling and stoma site marking created a low accumulation of self-efficacy value in ETNs. Scholz \& Schwarzer (2005) explained that a person's statement such as "I believe that I am capable of doing" is a manifestation of self-efficacy. Self-efficacy is a belief about ability to organize and perform any action (Pajares \& Urdan, 2006). Self-efficacy does not happen scientifically but it strongly influenced by a specific tasks and situations. Self-efficacy determines how much efforts will be done, how strong the efforts, and how long the efforts will be survived against the challenges encountered (Pajares, 2002).

Relationship between the Knowledge and SelfEfficacy About Counseling and Stoma Site Marking in ETNS

The chi square test showed that there was a statistically significant correlation between the knowledge and selfefficacy ( $p=0,008, \mathrm{OR}=3,808$ ).

Table 2: Relationship between Knowledge and Selfefficacy about Counseling and Stoma Site Marking in ETNs in Indonesia

\begin{tabular}{|c|c|c|c|c|c|c|c|c|}
\hline Knowledge & \multicolumn{4}{|c|}{ Self-efficacy } & Total & $P$ value & OR & (95\% Cl) \\
\cline { 2 - 6 } & Low & $\%$ & High & $\%$ & & & & \\
\hline Less & 21 & $41.7 \%$ & 13 & $19.3 \%$ & 34 & 0.008 & 3.808 & $1.4999-9.673$ \\
\hline Good & 14 & $20.3 \%$ & 33 & $26.7 \%$ & 47 & & & \\
\hline
\end{tabular}

Table 2 explained that from 34 ETNs in less of knowledge, 21 people (41.7\%) of whom had low selfefficacy. The table also showed that from 47 ETNs with a good knowledge only 14 people $(20.3 \%)$ of whom had low self-efficacy about counseling and stoma site marking. Further, the table showed that OR value is 3.808 (95\% CI: 1.499-9.673). It means that ETNs in good knowledge tends to have a high self-efficacy as well as 3.808 times than ETNs in less knowledge.

Self-efficacy is determined by a person's knowledge about object (Bandura, 1997). Baich et al., (2010) mentioned ETN as a nurse graduated of an accredited school or educational program called ETNEP (Enterostomal Therapy Nurse Education Program). In curriculum of ETNEP counseling and stoma site marking are an important part of stoma therapy programs. This was explained that ETN has been equipped with knowledges and skill about counseling and stoma site marking. Accordingly, ETN should have a high self-efficacy related to counseling and stoma site marking. ETN also should know that counseling and stoma site marking are necessary for patients prior to surgery. This statement supported by Colwell and Gray (2007) about the effects of preoperative counselling and education concluded that the intervention group given preoperative counseling more quickly understand about colostomy than the control group. The intervention group was shorter in terms of length of stay, then the number of visits due to complications of stoma in intervention group was minimal. As well as, the effectiveness of stoma site marking according to Baykara et al., (2014) explained that the incidence of complications was higher in patients who did not perform stoma site marking. Many previous research recommended all patients with stoma surgery should be counseled and sited marking before surgery to improve patient independence, decrease length of staying and reducing incidence of postoperative complications (Stelton et al., 2015).

Implementation of counseling and stoma site marking is not a convenient job, especially with less supportive by hospitals surrounding. It means that there are no habits of nurses doing counseling and stoma site marking yet, besides there is no standard operational procedures about counselling and stoma site marking. Based on this condition, there is no acknowledgment that ETN is professionally considered responsible for it. To implement the counseling and stoma site marking throughly needed unusual belief that it can be applied in 
many challenges. This represents one of the dimensions of self-efficacy that is magnitude (Bandura, 1997). Magnitude is the dimension of self-efficacy that refers to the level of difficulty of a particular task which is believed to be solved. Individuals with high magnitude self-efficacy will be able to complete the task as hard as any, while individuals with low magnitude self-efficacy will only be able to solve simple and simple behaviors (Lenz \& Bagget, 2002; Pajares, 2002; Pajares \& Urdan, 2006). Related to this study, ETN with high magnitude self-efficacy will tend to have confidence that they are able to do counselling and site marking stoma even with environment that does not support, or other obstacles which certainly is not easy. The existing difficulties will not be a reason for them to feel inadequate as long as the knowledge and skills related to the thing to be done are at a good level.

The existence of the relationship between knowledge with ETN self-efficacy in this study is proved by statistical test results that $p$ value is $<0.05$. This is consistent with the study by Cross Roe \& Wang (2014) that states an intimate relationship between knowledge with the nurse's self-efficacy. The lack of knowing the nurses about skin care, injuries and stoma is the main factor causing low self-esteem or self efficacy of nurses in performing stoma treatments. Bandura (1997) said that someone with increased knowledge will affect the improvement of the person's self-efficacy. Self-efficacy is a mediator between a person's knowledge with the behavior.

There is considerable research that examines the relationship between one's knowledge and self-efficacy. Research by Hessler (2015) on knowledge and selfefficacy nurse practitioners in preventing childhood obesity proves that increased knowledge will improve nurse self-efficacy. Similarly, the study by Nakhaei \& Mofrad (2015) also explains that there is a relationship between nurse knowledge with nurse self-efficacy $(\mathrm{r}=0.271$ and $p=0.033)$. Nakhaei \& Mofrad (2015) conducted the study by looking at the relationship between nurse knowledge and nurse self-efficacy in operating infectious control principles in the operating room. This study recommends that nurse knowledge improvement strategies should be promptly implemented as nurse knowledge upgrading will be followed by improvements in their self-efficacy as well. Similarly, several other studies that also discuss self-efficacy nurses where the conclusion is basically the knowledge and attitude. Self-efficacy is a factor that determines the success of nurses in implementing clinical practice so that it can be concluded that the hospital needs to consequently review its staff related to educational needs, scale of priority knowledge (specificity for each unit of care), improved staffer's motivation and improved working environment (Gould \& Chamberlain, 1994).

\section{CONCLUSION}

The implementation of counselling and stoma site marking prior to surgery can reduce the risk of complications and improve the quality of life in patients. ETN is a nurse who can provide enterostomal therapy, performing care stoma, wound and continental care. Theoretically kowledge and self-efficacy of ETNs plays vital role in application of counselling and stoma site marking. ETN is expected to play an important role in preparing patients for stoma surgery including counselling and site marking but the reality they did not applied it well. The findings of this study showed that there is a significant relationship between the knowledge and self efficacy about counseling and site marking stoma in ETNs. Bandura (1997) said that someone with increased knowledge will affect the improvement of the person's self-efficacy. Self-efficacy is a mediator between a person's knowledge with the behavior. It is expected that every healthcare service with stoma patient improve ETNs knowledge about counselling and stoma site marking periodically.

The suggestion of further research is a discussion on factors related to implementation of counseling and stoma site marking. The factors include education level ofETNs, the management of organisation around ETNs, work lists of ETNs, support system from colleagues, availability of facilities and infrastructure that directly or indirectly affect how the application of counselling and stoma site marking by ETNs in the hospital. Further research aims to emphasize the number of stoma complication events can be minimized one of them by increasing the role of ETNs.

\section{ACKNOWLEDGEMENT}

The first gratitude is delivered to the Faculty of Nursing, University of Indonesia which facilitated the administration in this research. President of InWOCNA and ETNs involved in this study, thank you as much as possible for time and participation. Finally to all research teams and colleagues, as well as families who have supported so that this research can be resolved properly. 


\section{REFFERENCES}

American Cancer Society (2017). Colorectal Cancer Fact \& Figure 2017-2019. Retrieved from: https://www.cancer.org/content/dam/cancer-org/research/cancer-facts-and-statistics/colorectal-cancer-factsand-figures-2017-2019.pdf

Baich, L., Wilson, D. \& Cummings, G. G. (2010). Enterostomal Therapy Nursing in the Canadian Home Care Sector What Is Its Value. Journal of Wound Ostomy \& Continence Nursing, 37(1), pp 53-64.

Bandura, A. (1997). Self-efficacy the Exercise of Control. WH Freeman and Company, New York.

Baykara, Z. G., Demir, S. G., Karadag, A., Harputlu, D., Kahraman, A., Karadag, S., Hin, A. O., Togluk, E., Altinsoy, M., Erdem, S. \& Cihan R. (2014). A Multicenter retrospective study to evaluate the effect of perioperative stoma site marking on stomal and peristomal complication. Ostomi Wound Management, 60(5), pp 16-26.

Bobbitt, P. (2003). The Shield of Achilles: War, Peace and the Course of History. New Ed edition, Penguin Books, London.

Colwell, J. C. \& Gray, M. (2007). Does Preoperative Teaching and Stoma Site Marking Affect Surgical Outcomes in Patients Undergoing Ostomy Surgery? Journal Wound Ostomy Continence Nurse, 34(5), pp 492-496.

Cronin, E. (2012). What the patient needs to know before stoma siting: an overview before Stoma Siting : an Overview. British Journal of Nursing, 21(22), pp 1304-1308.

Cross, H. H., Roe, C. A. \& Wang, D. (2014). Staff nurse confidence in their skills and knowledge and barriers to caring for patients with ostomies. Journal of Wound Ostomy \& Continence Nursing, 41(6), pp 560-565.

Gould, D. \& Chamberlain, A. (1994). Infection control as a topic for ward- based nursing education. Journal of Advanced Nursing, 20(2), pp 275-282.

Hunt, D. P. (2003). The concept of knowledge and how to measure it. Journal of Intellectual Capital, 4(1), pp 100113.

Indonesian Ostomate Association (INOA) (2010). Colorectal cancer: the old desease but new problems. Warta INOA. Retrieved from: http://dokumen.tips/documents/warta-inoa.html

International Ostomy Association (2004) Charter of Ostomate Rights. Retrieved from: http://www.ostomyinternational.org/about-us/charter.html

Lenz, E. R. \& Baggett, L. M. S. (2002). Self Efficacy in Nursing: Research and Measurement Perspectives. $1^{\text {st }}$ edition, Springer Publishing Company, USA.

Maryunani, A. \& Haryanto (2016). Modern stoma care. Salemba Medika, Jakarta.

Ministry of Health Indonesia (2012). National guidelines for colorectal cancer services. Retrieved from: http://kanker.kemkes.go.id/guidelines/PNPKkolorektal.pdf

Nakhaei, M. \& Mofrad, S. A. (2015). Investigating Nurses' Knowledge and Self- efficacy Regarding the Principles of Infection Control in the Operating Room, Modern Care Journal, 12(2), pp 79-83.

Pajares, F. \& Urdan, T. (2006). Self-efficacy beliefs of adolescent. Information age publishing, USA.

Pajares, F. (2002). Overview of social cognitive theory and of self-efficacy. Retrieved from: http://www.uky.edu/ eushe2/Pajares/eff.html.

Person, B., Ifargan, R., Lachter, J., Duek, S. D., Kluger, Y. \& Assalia, A. (2012). The impact of preoperative stoma 
site marking on the incidence of complications, quality of life, and patient's independence. Diseases of the Colon and Rectum, 55(7), pp 783-787.

Pittman, J., Bakas, T., Ellett, M., Sloan, R. \& Rawl, S. M. (2014). Psychometric evaluation of the ostomy complication severity index. Journal of Wound, Ostomy, and Continence Nursing: Official Publication of The Wound, Ostomyand Continence Nurses Society/WOCN, 41(2), pp 147-157.

Scholz, U. \& Schwarzer, R. (2002). Is general self-efficacy a universal construct? Psychometric findings from 25 countries. European Journal of Psychological Assessment, 18(3), pp 242-251.

Stelton, S., Zulkowski, K. \& Ayello, E. A. (2015). Practice implications for peristomal skin assessment and care from the 2014 world council of enterostomal therapists international ostomy guideline. Advances in Skin \& Wound Care, 28(6), pp 275-284.

Swan, E. (2011). Colostomy, management and quality of life for the patient. British Journal of Nursing, 20(1), pp 24-28.

World Council of Enterostomal Therapists (2000). Code of nursing practice: Member's handbook, appendixA. World Council of Enterostomal Therapist, Canada.

Zulkowski, K., Ayello, E. A. \& Stelton, S. (2014). WCET. WCET International Ostomy Guideline, Perth, Australia. 